specific stimulus. For example, alone in a crib a baby may twist and coo spontaneously, in response to nothing in particular.

When left alone in a room. a dog may pad back and forth, sniff, perhaps pick up a ball drop it and play with it. Neither is responding to stimuli in the outside world. They are operating on the world."

There is no mention of temporal priority. This is unfortunate because temporal priority is easy to establish. To decide whether something is respondent or operant (reflex or action) is a harder task. Consider blinking and urination which can be either.

In consequence, if we reject the temporal criterion then we will be left with three categories, as follows: firstly those where the behaviour is classical, secondly where it is operant and thirdly those where the conditioned behaviour has both classical and operant components.

In another text ${ }^{2}$ no definition for classical conditioning is given, only the example of a child ('little Albert') associating a loud noise (unconditioned stimulus) with the appearance of a rat (conditioned stimulus). In operant conditioning "making reinforcement contingent upon a response increases the rate of emission of that response".

The example is drawn from an experiment by Keehn (1967) in which students were trained to increase their frequency of blinking without being aware of it.

So this text emphasises the pattern of the association in time rather than whether the response is an action or a reflex.

Let us go with the second definition which prioritises the association in time. What about pad and bell training? The first thing to touch upon is that it is aversive. However there is nothing in the description of classical and operant conditioning to indicate that they would not apply to punishment. Indeed the example of 'little Albert' for classical conditioning provided in the second text above is aversive.

Even using the pattern of temporal association it is still difficult to say which type of conditioning applies to pad and bell training. The problem is that both types of conditioning could apply to a successful outcome. Supposing the child urinates (conditioned stimulus) and wakes up because of the alarm (unconditioned stimulus) and then after a while awakens because of the impetus to urinate, then this is indistinguishable from other examples of classical conditioning.

The events for instance could enter into one to one correspondence with the events in Pavlov's experiments with dogs.

Or supposing the child urinates and wakes up because of the alarm. Then it is just as true to say that the punishment of awakening is dependent on the act of urinating. So the child stops urinating at night and thereby avoids the punishment. This is indistinguishable from other examples of operant conditioning on the aversive model.

The conditioning process could be either classical or operant. It would be classical if the neutral stimulus of voiding came to be associated with an aversive stimulus leading to wakefulness and it would be operant if it was thereby avoided.

Which explanation applies depends on the individual child. If anecdotal accounts are correct then most children successfully treated with the pad and bell treatment sleep through the night without voiding which can therefore be explained in terms of operant conditioning.
Colin Dewar,

24 Elmwood Gardens,

Lenzie,

Glasgow G66 4EW,

Scotland.

References

1. Introduction to Psychology. Hilgard RE, Atkinson RL, RC Harcourt. Brace Jovanovich, Inc.

2. Seminars in Psychology and the Social Sciences. Tantam D, Birchwood M (eds). Royal College of Psychiatrists.

\section{Heavy general hospital case notes}

Sir - The article Heavy general hospital case notes: a simple case-finding method for psychiatric problems by Williams CJ, House A, Holmes J, Stewart A' is very interesting.

I would suggest that a further study to determine the actual types of admissions and whether the types of admission are repetitive for the same organ system or disease process would be helpful for the non-psychiatrist, psychologist in dealing with repetitive patient.

The authors obviously provide a very thought-provoking and well written paper, and it would be interesting to see a continuation of this type of research.

John J O'Connor,

Diplomatic American Board Colon and Rectal Surgery, 11125 Rockville Pike 308, Rockville,

Maryland 20852, USA.

1. Ir J Psych Med 1999; 16(4): 123-6

\section{Letters to the Editor}

should be addressed to:

The Editor

Irish Journal of Psychological Medicine

25 Adelaide Street

Dun Laoghaire

Co Dublin.

Fax: 01-280 7076

Email: psychological@medmedia.ie 